\title{
DESIGN PARA INOVACÃO SOCIAL: UMA EXPERIENCIA PARA INĆLUSÃO DO TEMA COMO ATIVIDADE DISCIPLINAR
}

\section{DESIGN FOR SOCIAL INNOVATION: AN EXPERIENCE FOR INCLUSION OF THE TOPIC AS DISCIPLINARY ACTIVITY}

Liliane Iten Chaves ${ }^{1}$

Ken Flavio Ono Fonseca ${ }^{2}$ 


\section{Resumo}

O design para a inovação social é uma abordagem relativamente recente do design para a sustentabilidade, que trata de iniciativas de comunidades criativas que possam levar a uma descontinuidade dos padrões atuais de produção e consumo. Entende-se por comunidades criativas iniciativas voluntárias de um grupo de pessoas, que se unem para resolver problemas do dia-a-dia de forma colaborativa e participativa.

Tal pesquisa está atrelada a uma rede internacional, denominada DESIS (Design de Sistemas para a Inovação Social e Sustentabilidade) presidida por Ezio Manzini, que possui laboratórios colaborativos por todo mundo. No Brasil a rede possui cinco laboratórios.

$\mathrm{O}$ artigo descreve as atividades relacionadas com as disciplinas ministradas com esta temática, da rede na UFPR, durante os anos de 2009 a 2014. Assim, o artigo dá uma breve apresentação da rede e do contexto em que a prática didática teve seu desenvolvimento.

Palavras-Chave: Design para a sustentabilidade, inovação social, comunidades criativas.

\section{Abstract}

Design for social innovation is a relatively recent approach of the Design for sustainability, which deals with initiatives from creative communities that can lead a discontinuity of current patterns of production and consumption. Creative communities are Design initiatives for social innovation, a group of people, volunteers, which unite themselves in order to resolve daily problems in collaborative and participative forms.

This research is linked to an international network called DESIS (Design of Systems for Social Innovation and Sustainability), which president is called Ezio Manzini and possesses collaborative laboratories all over the globe. In Brazil, the network has five laboratories.

The article describes the activities related to the subjects given with this theme, from UFPR's network, from 2009 to 2014. This way, the article gives a brief presentation of the network and from the context in which the practical didactic developed.

Keywords: Design for sustainability, social innovation, creative communities.

ISSN: 1808-3129
${ }^{1}$ Liliane Iten Chaves

$\mathrm{PhD}$ em Disegno Industriale e Comunicazione Multimediale pelo Politecnico di Milano (Itália) lilianeitenchaves@id.uff.br
${ }^{1}$ Ken Flavio Ono Fonseca

Universidade Federal do Paraná. Departamento SACO-

DE, Curso de Graduação em Design

ufpr.ken@gmail.com 


\section{INTRODUÇÃO}

O design para a Inovação Social é uma área recente de pesquisa, ensino e prática do design para a sustentabilidade, área esta que vem sendo desenvolvida para suprimir a necessidade de uma abordagem mais radical frente aos padrões atuais de consumo e produção.

Manter a qualidade de vida para uns e possibilitar que os menos favorecidos possam ascender a uma boa qualidade de vida é um desafio enorme, ainda hoje não atingido mesmo com os atuais avanços e inovações tecnológicas.

Desafio ainda maior nos apresenta um futuro próximo, se considerarmos os estudos que demonstram que nos próximos 50 anos teremos que viver com uma quantidade de apenas $10 \%$ dos recursos hoje consumidos, dados estimados que são conhecidos por fator 4 e 10 (KAZAZIAN, 2005, p. 63).

Os princípios Fator 4 e Fator 10 dão uma ilustração simples e eficiente da desmaterialização. Foram respectivamente elaborados em 1997 por Von Wiezsaecker (diretor do Instituto Wupperthal) e Schmidt-Bleek a partir de 1994. Para facilitar o acesso dos países em desenvolvimento ao crescimento, preservando ao mesmo tempo os recursos e evitando maior poluição, eles preconizam uma redução dos fluxos de matéria na economia: uma divisão por quatro daqui a vinte ou trinta anos e por dez daqui a cinquenta anos." (KAZAZIAN, 2005, p. 63)

Neste mundo onde teremos que consumir muito menos do que os padrões atuais, há a exigência de uma mudança drástica, uma ruptura com os padrões atuais de produção e consumo das populações que se encontram nos países de industrialização madura. Por outro lado, há a necessidade de se motivar as populações dos países que estão alcançando um melhor padrão de consumo, como por exemplo o BRIC (Brasil, Rússia, Índia e China), a adotarem novos padrões, buscando satisfazer suas necessidades com outros modelos de acesso, não sendo necessariamente pela aquisição de novos produtos (MANZINI, 2008, p. 47-51).

A mudança exigida para a sustentabilidade do planeta, ou mais precisamente da continuidade da raça humana no planeta, deve ser tão drástica, que exige a incorporação de inovações do tipo radicais e não incrementais. As inovações incrementais são aquelas introduzidas paulatinamente no nosso cotidiano, de forma que são incorporadas gradativamente, sem haver grandes mudanças. Seria o que se chama de redesign do existente (MANZINI; VEZZOLI, 2002, p. 20). As inovações radicais, por outro lado, são as que conseguem romper os padrões normais, ou melhor entendidos pelo termo em inglês "mainstream", e criar novas possibilidades.

O design para a sustentabilidade teve seu início voltado ao redesign do existente, criando produtos à partir de materiais com menor impacto ambiental, minimizando o uso de recursos, criando objetos mais duráveis, desmontáveis e reciclados e/ ou recicláveis. Porém, a mudança incremental, apesar de ser um excelente caminho, poderá não dar conta da mudança necessária.

Buscando a desmaterialização, os designers preocupados com o meio ambiente, apostaram no desenvolvimento dos Sistemas Produto Serviços, mas conhecidos pela sigla inglesa PSS (Product Service System). A ideia principal era a de dar acesso 
a soluções, satisfazendo os usuários, sem a criação e produção de novos produtos, reduzindo o consumo de novos e incrementando o compartilhamento (UNEP, 2001, p. 10-14). Assim, produtos compartilhados poderiam possibilitar a não fabricação de novos. Além disto, poderiam levar a uma mudança indireta das empresas, que seriam responsáveis por um melhor uso dos objetos, pelo recolhimento no fim-de-vida e por serem motivadas a aumentar a duração dos produtos, através de manutenção mais adequada, etc.

Atentos a esta possibilidade, os designers preocupados com o meio ambiente, passaram a desenvolver habilidades ligadas à gestão, criação e comunicação de Sistemas Produto-Serviços. Nota-se que aos poucos os cursos de design no Brasil estão incorporando disciplinas atentas a estas novas ferramentas.

Os Sistemas Produto Serviços não são uma garantia de menor impacto ambiental. Pode-se observar que em alguns exemplos há um aumento de transporte ou embalagem (MANZINI, 2008, p. 35-36).

No entanto, a incorporação destas novas habilidades nas atividades dos designers permitiu expandir a ação destes e podem servir para um novo papel que vem sendo exigido dos designers, o de experts em design. 


\section{DESIGN PARA A INOVAÇÃO SOCIAL}

Em seu mais recente livro, Manzini (2015, p. 1), nos apresenta a necessidade de repensar o papel do designer.

Hoje em dia, nos países ditos de industrialização madura, ou ricos, a crise econômica exigiu que as pessoas repensassem seus modos de vida, buscando viver melhor, consumindo muito menos. Repensando o conceito de bem estar baseado no consumo. Por outro lado, os países onde a economia está em rápida ascensão, as pessoas estão sofrendo uma transformação socioeconômica profunda, tendo que redefinir, também, suas formas de bem estar (MANZINI, 2015, p. 24).

Manzini (2008, p. 47-51) nos apresenta três hipóteses de trabalho relacionadas ao bem estar e a atual crise ambiental e social. Aqui descreveremos de forma leviana, apenas para que se possa posteriormente refletir sobre os casos de inovação social levantados durante as disciplinas ofertadas.

1) Crise dos bens comuns: são bens que são de todos e não são de ninguém, como é o caso da água e dos locais públicos como praças e parques, mas também a segurança e o sentimento de pertencimento. Estes bens não podem ser comprados e vendidos, portanto, foram colocados fora das prioridades do padrão hegemônico.

2) Desaparecimento do tempo lento e contemplativo: este é o tempo para "fazer nada", ou tempo para contemplarmos de forma lenta e profunda qualidades de nossas vidas. Com a saturação dos afazeres e a aceleração das ações, o tempo de reflexão passou a ser escasso.

3) Difusão dos bens remediadores: são considerados pelo autor "produtos ou serviços que tentam tornar aceitável um contexto de vida que é, por si mesmo, altamente deteriorado". Ou seja, bens e serviços para uso e consumo privados que tem como premissa a melhoria da vida (novas máquinas de lavar roupas, garrafa de água mineral, pacotes de turismo, etc.). "O caráter comum desses bens é que seu uso ou consumo não melhora a qualidade de vida ou abre novas possibilidades para os usuários" (MANZINI, 2008, p. 50).

Surgem, então, rupturas ao modelo hegemônico verificadas de forma pulverizada, em iniciativas de pequenos grupos locais, chamados por Manzini (2008, p. 64-65) de "comunidades criativas", isto é, grupo de voluntários que resolvem se unir para resolver problemas do dia-a-dia de forma colaborativa e participativa, incorporando hábitos que podem resultar em estilos de vida mais sustentáveis (MERONI, 2007, p. 9-15).

Assim, o tema do Design para Inovação Social e Sustentabilidade (DESIGN FOR SOCIAL INNOVATION AND SUSTAINABILITY, 2012) trata destas iniciativas locais, capazes de criar rupturas nos padrões atuais de consumo e produção, contribuindo para a sustentabilidade. O tema é abordado pela rede DESIS (DESIGN FOR SOCIAL INNOVATION AND SUSTAINABILITY), estruturada através de escolas, instituições, companhias e outras organizações não lucrativas, que promovem e dão suporte a pesquisas e práticas sobre essas iniciativas locais 
Assim, neste mundo, no qual a constante transformação faz com que todos e qualquer pessoa faça o design e o redesign de sua existência, onde as tecnologias de informação e comunicação possibilitam redes distribuídas interconectadas, qual seria o novo papel dos designers? E como deve ser o redesign deste novo papel dos designers?

Para Manzini, os designers podem surgir como experts em design, que graças a habilidade com ferramentas e métodos projetuais, podem ajudar não designers a orientar suas iniciativas (MANZINI, 2015, p. 1).

\section{REDE DESIS}

A rede DESIS, fundada e presidida por Prof. Ezio Manzini, tem por objetivo utilizar o pensamento e conhecimento de design para co-criar, com parceiros locais, regionais e globais, cenários, soluções e programas de comunicação socialmente relevantes (DESIGN FOR SOCIAL INNOVATION AND SUSTAINABILITY, 2012, p. 1).

Ela tem sua origem em três atividades que aconteceram entre os anos de 2006 a 2008, são elas:

1) O projeto, Emerging User Demands for Sustainable Solutions (EMUDE), financiado pela Comunidade Europeia no $6^{\circ}$ Programa Quadro, em 2006.

2) O documento interno da força-tarefa sobre Consumo e Produção Sustentáveis, do Ministério do Ambiente sueco e a UNEP (Programa das Nações Unidas para o Meio Ambiente ou United Nations Environment Programme), denominado, Creative Communities for Sustainable Life Styles (CCSL), em 2008.

3) E a Conferência Internacional Changing the Change, que aconteceu em Torino, nas atividades realizadas para Torino World Design Capital, também em 2008 (DESIGN FOR SOCIAL INNOVATION AND SUSTAINABILITY, 2012, p. 1).

Foram estas atividades que nortearam as ações hoje realizadas pela rede. Ainda hoje, os critérios de seleção de casos possuem como base o projeto EMUDE.

Hoje a rede DESIS consiste em uma constelação de laboratórios de design (design labs) inseridos em Escolas e Faculdades, que ativamente estão envolvidas em promover e dar suporte a mudanças que levem à sustentabilidade (DESIGN FOR SOCIAL INNOVATION AND SUSTAINABILITY, 2012, p. 3). Estes laboratórios trabalham de forma autônoma, mas estão interconectados.

Estes laboratórios estão espalhados por diversos países: Austrália, Bélgica, Botswana, Canada, Chile, China, Colômbia, Dinamarca, França, Índia, Itália, Japão, Quênia, Nova Zelândia, Holanda, Portugal, Suécia, Turquia, Reino Unido, África do Sul, Coréia do Sul, Estados Unidos, Brasil (DESIGN FOR SOCIAL INNOVATION AND SUSTAINABILITY, 2015).

No Brasil, a rede DESIS é coordenada por Carla Cipolla, professora adjunta da Universidade Federal do Rio de Janeiro, Instituto COPPE. Os outros grupos do DESIS brasileiro são (JOLY, 2015, p. 70-74): 
NAS DESIGN (Núcleo de Abordagem Sistêmica do Design), grupo de pesquisa situado no Departamento de Expressão Gráfica (EGR), do Centro de Comunicação e Expressão (CCE), da Universidade Federal de Santa Catarina (UFSC), em Florianópolis.

CEDTec (Centro de Estudos em Design e Tecnologia), núcleo de pesquisa situado dentro da Escola de Design da Universidade Estadual de Minas Gerais (UEMG), em Belo Horizonte.

Grupo DESIS UFRJ, núcleo de pesquisa dentro do departamento do Programa de Engenharia de Produção da COPPE, na Universidade Federal do Rio de Janeiro, no Rio de Janeiro.

NDS (Núcleo de Design e Sustentabilidade) é um núcleo de pesquisa que está inserido dentro do Departamento de Design, da Universidade Federal do Paraná (UFPR), em Curitiba.

UNISINOS DESIS, desde abril de 2014 foi incorporado ao DESIS Brasil o grupo de pesquisa da Universidade do Vale do Rio dos Sinos, dentro da Escola de Design, em Porto Alegre.

Estas instituições trabalham de forma colaborativa, no formato entre pares (peer-to-peer), sendo iniciativas isoladas, porém compartilhadas.

\section{DESIS NA UFPR}

Existem duas formas do designer participar nestas iniciativas de inovação social propostas pelo DESIS: o projeto pode acontecer com a comunidade ou para a comunidade. No primeiro, o designer irá atuar dentro do caso, como parceiro, em uma "pesquisa-ação". No segundo caso, o designer irá analisar iniciativas já existentes, identificando necessárias intervenções nas quais ele possua domínio (JOLY, 2015, p. 70-74).

No Departamento de Design da Universidade Federal do Paraná (UFPR), este segundo modelo foi escolhido como abordagem. Esta escolha teve como motivação diferentes objetivos.

1) Aproximar os estudantes dos cursos de graduação em design, cujas áreas são produto e gráfico, a conteúdos relacionados com design de produto-serviço e/ou design estratégico.

2) Fazer os estudantes de graduação e pós-graduação refletirem sobre o atual papel do designer nestas iniciativas, em discussões relacionadas não só ao tema da inovação social, mas também, quanto à sustentabilidade (ambiental, econômica, social e cultural), e os novos rumos da profissão em não mais lidar com produtos tangíveis, mas em ser especialista na gestão do design.

3) Criar e promover uma base de casos locais para posterior disseminação destes casos.

4) Apresentar aos estudantes estas iniciativas e promover a integração destes com elas, de forma que um número maior de casos possam contar com profissionais 
da área de design, pulverizando ações e não focando a ação em apenas um projeto específico.

No departamento de design da UFPR, foi escolhida como forma de atuação, na rede DESIS, a oferta de disciplinas. Assim, desde 2009 até final de 2014, a disciplina de Design de Sistemas para a Inovação Social foi oferecida cinco vezes, com um total de 60 estudantes até 2014.

\section{REDE DESIS: TOOLKIT DE COLETA DE CASOS}

Na disciplina optou-se por fazer o levantamento de dados em consonância com a rede DESIS. Esta rede possui um formato internacional, pré-estabelecido, para o levantamento dos casos de "comunidades criativas" e propõe uma sequência de atividades para os estudantes incrementarem estes casos. Para o desenvolvimento das atividades, o projeto DESIS fornece um "toolkit", conjunto de documentos e formatos de apresentação power-point, organizados em uma sequência de quatro passos:

a) Levantamento de casos promissores.

b) Coleta de dados e preenchimento da documentação dos casos selecionados.

c) Exercício de design através da organização de um workshop.

d) Disseminação dos resultados.

O DESIS sugere que as atividades sejam realizadas por grupos de 3 a 4 estudantes.

No primeiro passo, pesquisa de casos promissores, cada membro do grupo irá trazer três a quatro hipóteses de casos promissores de comunidades criativas a serem discutidas em sala de aula com o professor e os colegas. Os casos serão levantados com a ajuda da internet, de amigos, familiares, vizinhos, etc.

Os casos levantados devem se basear nos seguintes critérios, retirados do Projeto EMUDE. Para que as iniciativas sejam consideradas de interesse para a rede, neles os casos devem ser:

1) Soluções inovadoras: têm de ser organizações constituídas por diferentes atores sociais; os atores se auto-organizam para obter um resultado ou para abrir uma nova oportunidade na vida cotidiana; as soluções têm que ser inovadoras em relação à principal corrente (mais conhecida pelo termo em inglês main stream) de pensamento e de ação (pelo menos em relação aos lugares onde são observados).

2) Organizações de baixo para cima (bottom-up): os promotores das soluções devem ter uma relação "local", assim como os usuários finais, ou seja, empresários, ONGs, as instituições locais. Como a noção do que pode ser considerado como "local" é relativo, a rede DESIS considera uma iniciativa como "local" quando os promotores operam na escala dos bairros e/ou de uma pequena cidade, embora possam ser 
ligadas a organizações maiores e redes distribuídas.

3) Socialmente positivos: as soluções precisam regenerar o capital social e fortalecer o tecido social. Este efeito regenerativo pode ter lugar de forma direta (sendo uma meta formal da iniciativa) ou indiretamente (isto é, não é uma meta formal da iniciativa mas acaba acontecendo como resultado). É importante ressaltar que o objetivo social não deve ser o principal e único. Os programas de caridade e/ou de melhoria social, em si mesmos, não se inserem como modelos de novas oportunidades para a vida cotidiana de toda a sociedade.

4) Ambientalmente amigáveis: as iniciativas devem reduzir a média da pegada ambiental local. Não precisam ser iniciativas direcionadas, apenas, para resolver problemas como os resíduos para reciclagem, geração de energia renovável, a prevenção da poluição, etc. $O$ efeito regenerativo pode ter lugar, também, indiretamente (isto não é uma meta formal da iniciativa, mas, no entanto, isso acontece).

No passo 2, coleta de dados e preenchimento da documentação dos casos selecionados, as iniciativas aprovadas coletivamente pela turma como sendo promissoras, serão investigadas com maior profundidade através de entrevistas com as "comunidades" e visitas para observações no local.

No exercício de Design, passo 3, os estudantes irão organizar e participar de um workshop, cujo objetivo é a discussão e revisão das iniciativas levantadas para compreender quais são as possíveis contribuições que o designer poderia oferecer nelas, além de criar uma espécie de manual para a replicação da iniciativa em outro contexto.

Por fim, o passo 4, disseminação dos resultados, os resultados são apresentados em um seminário, cujos participantes seriam os estudantes, os participantes das iniciativas, ONGs e outros interessados na temática.

\section{RESULTADOS ALCANÇADOS}

A primeira vez que a disciplina de Design para a Inovação Social foi oferecida, em 2009, no Departamento de Design da UFPR, foi intitulada como Design para a Inovação Social e Sustentabilidade: identificação e avaliação de iniciativas de comunidades criativas. O formato escolhido foi de curso de extensão, tendo um total de 32 horas. Contou com nove participantes de diferentes áreas e instituições.

Os seguintes casos foram levantados:

Jardinagem Libertária: grupo de pessoas que plantam jardins em locais públicos. Eder Sam, Mariana Tomaz.

Bicicletada Curitiba: Grupo de pessoas que se encontram para andar de bicicleta juntos. Mariana Ordacowski e Rebeca Storrer.

Lavanderia compartilhada: uma área de lavanderia criada em um edifício para lavagem das roupas dos moradores. Nieli Proença, Rosana Vasques.

Moeda Social: no banco social, o consumidor troca reais pela moeda social em 
circulação no seu bairro ou cidade. No comércio local, ele ganha desconto ao pagar com esse dinheiro. Patrícia Mitie Kojima, Tássia Bianchini.

Em 2009, a disciplina foi ofertada como disciplina optativa para estudantes da graduação. Inscreveram-se 20 alunos e 5 casos levantados.

Carona Brasil: ferramenta online para pessoas compartilharem suas jornadas de carro. Erika Osti, Henrique Baptista, Lucas Martinichen, Rafaela Zeidler.

Casa da Videira: inspirar soluções domésticas em sustentabilidade ambiental vivendo e participando da comunidade local, através de exemplos de práticas sustentáveis simples de serem implantadas. Eduardo F. Rodrigues, Paola A. Andrade, Rafaela S. Romeiro

Cursinho em Ação: cursinho criado para a preparação para o vestibular por ex -alunos de forma voluntária. Felipe Leite, Franciele Abdnor, Mariana Moro, Tiago Volpato.

Freecycle: ferramenta online que promove a troca entre doadores de objetos. Felipe, Fernanda, Pedro, Luiz.

PROBEM: campanha de adoção de cães abandonados, promovido por voluntários, sem fim lucrativo que promove a educação da população para a prática e o convívio responsável com animais domésticos. João Pedro Marques Mion, Paulo Leonardo de Andrade, Rafael Pastorin and Sílvia Patiño

Em 2010, foi aberta uma disciplina para o mestrado stricto-sensu do Programa de Pós-Graduação em Design. A partir deste ano, apenas esta modalidade foi utilizada. A disciplina tinha 45 horas e foram coletados 3 casos. 11 alunos

Projeto Noé: Grupo de moradores que se encontram para planejar ações de melhorias em seu bairro. Débora Jordão Cezimbra Gláucia de Salles Ferro, Jair de Melo Jarek, Malis Maria Liebl Keil.

Instituto AgroEcológico: Grupo de profissionais de diferentes áreas recém formados que voluntariamente desenvolvem projetos relacionados a boas práticas de produção agrícola (agricultura familiar, agricultura orgânica, etc.). Isabela Mantovani Fontana, Patrícia Betti, Rafael Cialli, Simone Secheto.

Aldeia coWorking: Espaço condividido para escritórios de profissionais liberais. Carol Dorneles, Carolina C. Daros, Geisy Anny Venâncio.

Em 2012, foi oferecido uma disciplina no PPGDesign da UFPR, com 15 horas aulas, 1 crédito. Nesta versão, participaram mestrandos e doutorandos, pois o doutorado recém tinha sido aprovado no programa. Compareceram 12 estudantes. Neste curso, por causa da pouca disponibilidade de horas/aulas, os casos foram previamente pesquisados pela professora e apresentados para os estudantes, que passaram para a fase de entrevista e aplicação das ferramentas de design estratégico imediatamente. O caso "Freguesia do livro" foi trazido pelos próprios estudantes. Foram trabalhados 3 casos distintos que foram: 
Ciclovida UFPR: projeto de caráter multidisciplinar, que promove a mobilidade com uso da bicicleta. Bernadete Brandão, Guilherme Ferreira, Ken Fonseca, Vanessa C. Ambrosio.

Carona solidária na UFPR: organizar, à partir da criação de um site, caronas solidárias na UFPR, reduzindo a quantidade de pessoas que se deslocam sozinhas em seus carros. Denise Holtman, Elizabet Z. Rymsza, Clécio Zeithammer, Sandra Marchi.

Freguesia do Livro: iniciativa que promove o acesso a livros, através da coleta e distribuição destes. MarilnesPiekas, NaotakeFukushima, Adriana Duderstadt, Mariana Souto

Em 2014, foi oferecido uma disciplina com 45 horas, 3 créditos, Design e Inovação Social, com 16 alunos. Foram levantados 8 casos pelos estudantes. São eles:

Centro Comunitário Parque das Águas Claras: associação de uma comunidade de baixa renda, fundada pelos moradores, que sentiram a necessidade de se organizarem para lutar si. Isadora Dickie e Rodrigo Karam.

Brechó de Trocas na UniCuritiba: bazar solidário que tem por objetivo estimular a comunidade acadêmica a refletir sobre sua relação com o consumo, Curitiba/PR. Arabella Natal Galvão da Silva.

Caminhadas Observacionais de Curitiba: exercitar o senso de observação nos bairros de Curitiba. Reconhecer árvores. Discutir a destruição do patrimônio da cidade. Analisar aspectos da criatividade nas fachadas, esculturas, intervenções urbanas. Coletar conteúdos destinados a eventuais produções artísticas, Curitiba/PR. Caroline Müller e Luciane Scarante Busch.

Praça de Bolso do Ciclista: promove revitalização do espaço e um ambiente de convivência através de atividades culturais, arte, música e oficinas na praça. Anderson Trierveiler, Andréia Mesacasa, Carolina Daros, Juliana Mayumi, Vagner Martins.

Espaço Cultural Casa Iririú: local onde a comunidade encontra e promove oficinas culturais, apresentações artísticas, cursos, produções, exposições de arte entre outros eventos gratuitos. Edson Sidnei Maciel Teixeira.

Movimento de Mulheres da Primavera: promove a emancipação das mulheres nas esferas financeira, emocional e política, Guarapuava/PR. Ione Rodrigues Correia e Louise Clarissa Vendramini.

Grife Social "Omunga": empreendimento social que, por meio da mobilização, articulação, compaixão e ação, visa promover a educação em regiões de extrema vulnerabilidade social no Brasil e no mundo, Joinville/SC. Debora Barauna.

Bosque da Casa Gomm: um shopping center prevê a construção de uma rua, que dê acesso ao seu estacionamento, onde existe uma área pública tombada, significativa para a cultura, história e meio-ambiente da cidade de Curitiba. A missão da iniciativa é criar nesta área o Parque Gomm, como símbolo da retomada do planejamento urbano de Curitiba. Michele Zamoner e Renata Vavolizza

\section{ADAPTAÇÃO DO MÉTODO PARA O CONTEXTO}

Como exposto anteriormente, a disciplina tinha por objetivo não apenas o le- 
vantamento de casos, mas discutir o papel do designer neste processo atual de transformação e de aproximar os estudantes de ferramentas de design de serviço.

Uma vez que nem todos os participantes das disciplinas oferecidas tinham conhecimento sobre conteúdos relacionados com design para a sustentabilidade, foi necessário fazer uma introdução ao tema para que houvesse a compreensão de como casos de inovação social poderiam ser uma possibilidade de se repensar novos modelos de qualidade de vida e bem estar, a partir de um menor consumo. Além deste, foram abordados os seguintes conteúdos:

Panorama do design para a sustentabilidade: da escolha de materiais e novos estilos de vida.

O design estratégico e suas possibilidades no design social

Entender sobre casos de inovações promissores no âmbito do design para a sustentabilidade.

Analisar os casos levantados de iniciativas de comunidades criativas em Curitiba e regiões próximas.

Aplicar ferramentas do design estratégico nos casos analisados e propor melhorias dentro do âmbito do design.

O livro de Manzini (2008, p. 15-103), "Design para a Inovação Social: comunidades criativas, organizações colaborativas e novas redes projetuais", serviu de base para seminários, que aconteceram logo após a exposição inicial sobre o panorama do design para a sustentabilidade.

Os alunos deveriam ler previamente um capítulo por aula e, em conjunto, discutir o conteúdo relacionando-o com sua vivência pessoal.

Em seguida, os estudantes buscavam casos de interesse de inovação social e traziam para serem discutidos e aprovados em sala. Posteriormente, o toolkit da rede DESIS era utilizado, sendo feita entrevistas e pesquisa baseadas no método etnográfico, onde o pesquisador é um observador do caso, nos locais das iniciativas. Em todos os casos foram assinados termos de uso de imagem e dados para fins científicos, como estabelece o toolkit.

Como muitas vezes os estudantes não possuíam conhecimento e prática de ferramentas de design estratégico ou de serviço, estas ferramentas foram utilizadas, nos casos, com dois propósitos: análise/visualização e proposição de melhorias.

Para análise/visualização dos casos foram utilizadas as seguintes ferramentas e técnicas:

Matriz SWOT (Strenghts, Weaknesses, Opportunities, Threats: esta ferramenta serve para analisar as forças, oportunidades fraquezas e ameaças.

Mapa do sistema: é uma ferramenta que dá uma panorama das relações do sistema em estudo. Ela permite entender quais interações e fluxos são realizados com os atores da iniciativa: material, econômica ou de informação (JÉGOU; MANZINI; MERONI, 2004, p. 111). 


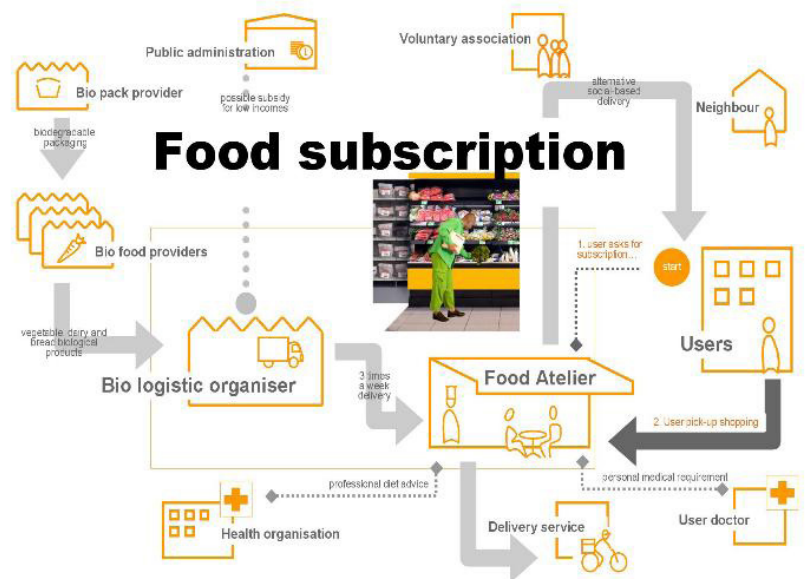

Figura 1: Mapa de Sistemas

Fonte: Jégou; Manzini; Meroni, 2004, p. 111

SDO MEPSS ${ }^{1}$ : Sustainability Design-Orienting Toolkit é um software online que permite fazer um check-list dos aspectos ambientais, sociais e econômicos do sistema atual ou futuro (HALEN; VEZZOLI, WIMMER, 2005, p. 115-116).

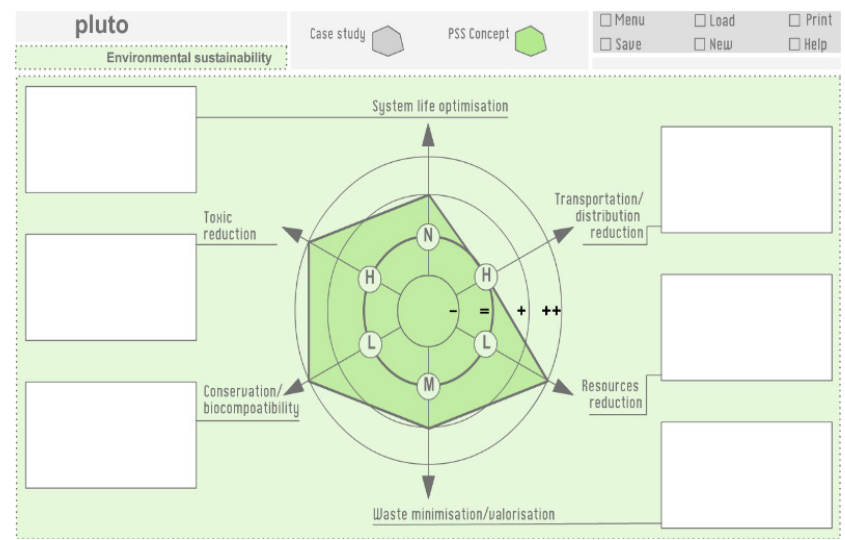

Figura 2: SDO-MEPSS

Fonte: Halen, C. van, Vezzoli, C., Wimmer, R., 2005

Para proposição de melhorias, foram utilizadas as seguintes ferramentas:

Customer Journey: é uma técnica que se propõe a investigar e analisar passo-a-passo a experiência do usuário no serviço analisado (CAUTELA, 2007, p. 115-116).

Matriz de polaridades: é uma ferramenta de construção de cenários, mais utilizada para brainstorm de novas ideias a partir de polaridades relacionadas à iniciativa e estabelecidas pelo designer.

${ }^{1}$ SDO MEPSS software desenvolvido durante o Projeto MEPSS (Methodology for Product Service System), financiado pela Comissão Européia em 2001 está disponível no endereço: http://www.mepss-sdo.polimi.it/mepss/website/mepss.html 


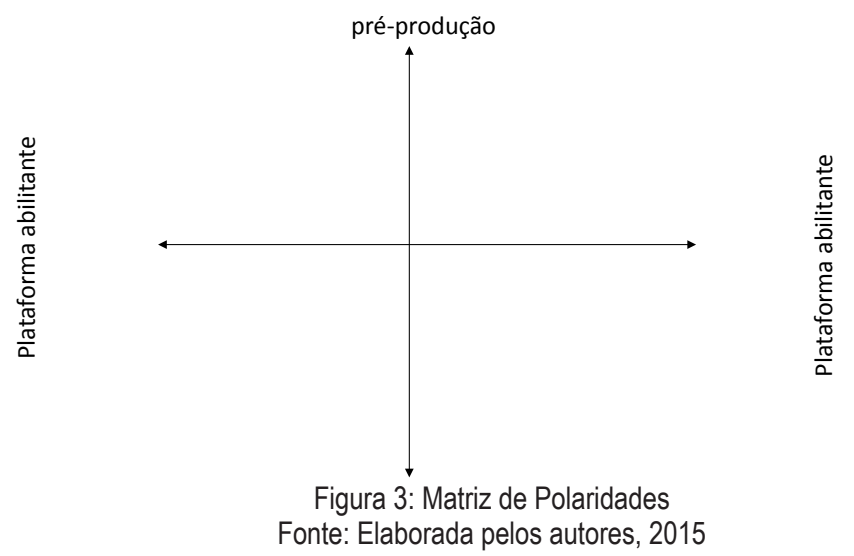

Story board: ilustra, no format de estórias em quadrinhos, as interações do usuário com o serviço (JÉGOU; MANZINI; MERONI, 2004, p. 112).

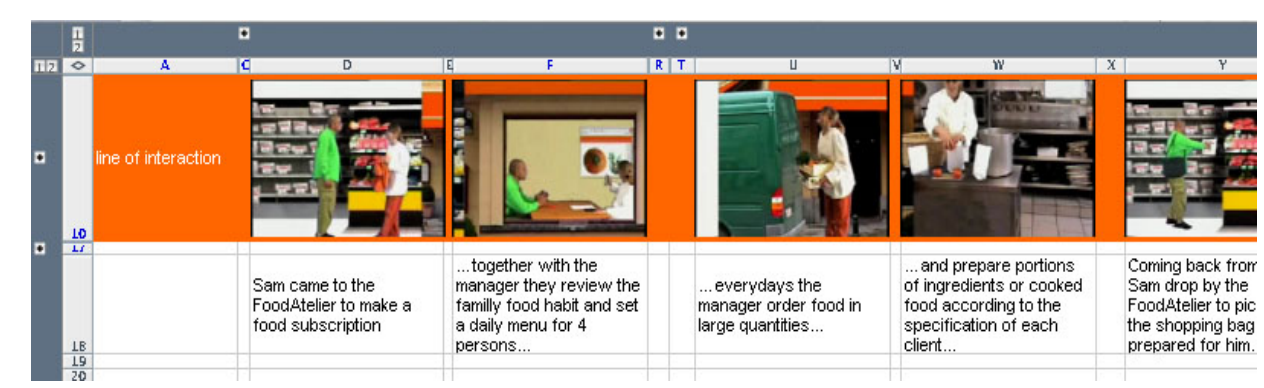

Figura 4: Story board

Fonte: Jégou; Manzini; Meroni, 2004, p. 112

Tabela dos atores, com descrição e papel de cada um dos atores (sejam pessoas ou instituições) envolvidos na iniciativa.

Mapa do sistema com as modificações realizadas após o uso das ferramentas de análise e desenvolvimento de melhorias.

SDO MEPSS: ambiental e social do novo sistema).

Síntese das vantagens ambientais, sócio-éticas e econômicas do novo sistema.

O tempo disponível nas disciplinas nem sempre permitiu o uso de todas as ferramentas. Em alguns casos foram suprimidas as ferramentas de melhoria das iniciativas.

\section{ANÁLISE DOS RESULTADOS}

Foram 23 casos de Inovação Social levantados de 2009 até 2014 . Na sua maioria são casos localizados na cidade de Curitiba e sua região metropolitana. No entanto, dois casos são da de Joinville, cidade situada a $132 \mathrm{~km}$ de Curitiba, porque os estudantes eram desta cidade.

Para o levantamento dos casos, a maioria dos estudantes ou já conhecia um exemplo, ou buscou com familiares e amigos. Alguns casos, como o do Cursinho em 
Ação, foram vivenciados pelos próprios estudantes. Em alguns casos, foram feitas pesquisas pela internet, como é o caso do site Carona Solidária e Freecycle. Estes dois casos foram aceitos pelo grupo, mas não são considerados ideais, pois não existe uma interação pessoal dos envolvidos para a criação e execução do serviço. Naturalmente que a troca dos objetos (Freecycle), e as caronas (Carona solidária) só se efetivam com os usuários agindo.

Abaixo estão relacionados os casos por macro temas:

Mobilidade: Ciclo vida, Bicicletada Curitiba e Carona solidária, Caminhadas Observacionais.

Criação e organização de Espaços públicos comuns: Praça de bolso do ciclista, Espaço cultural Iririú, Jardinagem Libertária, Bosque da Casa Gomm.

Facilidade vida cotidiana: Lavanderia compartilhada.

Diferentes sistemas de troca: Moeda Social, Brechó de Trocas na UniCuritiba, Freecycle.

Iniciativas para o bem comum: Casa da Videira, PROBEM, Cursinho em Ação, InstitutoAgroEcológico, Grife Social Omunga.

Associações: Projeto Noé, Centro Comunitário Parque das Águas Claras e Movimento de Mulheres da Primavera.

Trabalho: Aldeia coWorking.

Os casos de espaços comuns aumentaram nas últimas edições da disciplina, talvez uma demonstração das transformações que a própria cidade vem sofrendo.

Os casos de mobilidade parecem ser reincidentes e bastante visados. O problema da qualidade do transporte urbano parece fazer com que iniciativas deste âmbito sejam mais visíveis pelos estudantes. Observa-se que tanto a Bicicletada de Curitiba, quanto as Caminhas Observacionais são iniciativas que resgatam o reconhecimento do território e o sentimento de pertencimento.

Os casos que envolviam associações de moradores não eram incentivados a serem investigados e só foram aceitos porque apresentaram elementos que os diferenciavam de outras associações de moradores comuns.

O caso da lavanderia coletiva ter sido aceito pelos participantes foi pela originalidade da iniciativa no contexto da época em Curitiba. Casos de lavanderias compartilhadas são comuns em países como Suiça e Alemanha.

Verifica-se que existe uma forte tendência em que os estudantes buscassem casos relacionados com os bens comuns. Talvez por serem mais visíveis, ou talvez, por que de fato a ausência dos bens comuns, conforme declarado por Manzini (2008, p. 47-52), afete diretamente a vida social dos estudantes, de forma que estes estavam mais sensibilizados quanto a estas iniciativas. 


\section{CONSIDERAÇÕES FINAIS}

A disciplina foi oferecida em diversos formatos: curso de extensão, disciplina optativa para a graduação em design e disciplina para o mestrado e doutorado no PPGDesign da UFPR.

Este último tem sido o formato adotado, uma vez que a professora é colaboradora deste Programa de Pós-Graduação. Além disto, compreendeu-se que a maturidade dos estudantes, aliada com a maior experiência destes, permitiu um avanço maior no uso das ferramentas em contraste com os estudantes da graduação. Quando aplicada com estes, a disciplina demonstrou ter poucas horas para um conteúdo de design estratégico aos quais os estudantes não estavam habituados. Esta falta de habilidade com as ferramentas foi a maior dificuldade encontrada ao ministrar a disciplina, e portanto, demonstrou ser um aspecto motivador.

As ferramentas de design estratégico, muitas vezes, demonstraram ser de difícil aplicação pelos estudantes de design. Uma das maiores dificuldades para os estudantes era conseguir manipular variáveis não tangíveis como os serviços. Fora os participantes do curso de extensão, os demais se sentiram motivados em entender e aplicar ferramentas de design estratégico.

O curso de extensão apresentou ser uma boa opção para este conteúdo, pois permitia a abertura de inscrição para a comunidade em geral, recebendo diversos tipos de profissionais que vieram enriquecer o exercício proposto. Porém, estes estudantes originários de outras áreas possuíam pouca intimidade com a temática do design, menos ainda com o design para a sustentabilidade e design para a inovação social. Deve-se considerar estes aspectos na organização de um curso de extensão sobre esta temática, redimensionando a quantidade de horas e reformulando o conteúdo proposto.

O tema design para a inovação social ainda é bastante confundido no Brasil com design social. Os estudantes tiveram dificuldade em entender que o social, neste contexto, tratava de novas relações sociais e não de ajuda para um classe de pessoas menos privilegiada. Em geral, os estudantes buscavam casos de cooperativa de trabalhadores, muitas vezes relacionadas com a coleta seletiva e reciclagem de lixo.

Um dos objetivos da oferta desta disciplina é disseminar os casos de inovação social e motivar a participação pelos estudantes. É por isto que se optou em levantar os casos e não na criação de um projeto de inovação social a ser seguido. Muitos dos estudantes se sentiram motivados em participar e passaram a defender as iniciativas após as visitas e entrevistas. Eles passaram a sentirem-se atores ativos. Seria necessário um projeto específico que permitisse compreender se os egressos dos cursos continuaram as participações e se as iniciativas sofreram algum impacto, por menor que seja, com as relações estabelecidas com os estudantes.

\section{REFERÊNCIAS BIBLIOGRÁFICAS}

CAUTELA, C. Strumenti di Design Management, Milão: Francoangeli, 2007.

DESIGN FOR SOCIAL INNOVATION AND SUSTAINABILITY, 2015, Disponível em: 
<http://www.desis-network.org/content/desis-labs>. Acesso em: 02/05/2015. DESIGN FOR SOCIAL INNOVATION AND SUSTAINABILITY. DESIS Network: design for social Innovation and Sustainability. Disponível em: <http://www.desis-network.org/ sites/default/files/files/desis_brochure.pdf>. Acesso: 02/05/2015.

HALEN, C. VAN, VEZZOLI, C., WIMMER, R. Methodology for Product Service System Innovation: how to develop clean, clever and competitive strategies in companies. Assen: Koninjkijke Van Gorcum, 2005.

JÉGOU, F.; MANZINI, E.; MERONI, A. Design Plan: a design tool box to facilitate solution oriented partnerships. In: Manzini, E.; Collina, L., Evans, S. (Ed.) Solution Oriented Partnership: how to design industrialised sustainable solutions. Bedforshire: Cranfield University, 2004.

JOLY, M. P. Design para a Inovação Social e a Rede DESIS no Brasil. Dissertação (Mestrado em Engenharia de Produção) - COPPE, UFRJ, Rio de Janeiro, 2015.

KAZARIAN, T. Haverá a Idade das Coisas Leves: design e desenvolvimento Sustentável. São Paulo: Editora SENAC, 2005.

MANZINI, E. Design, When Everybody Designs: an introduction to design for social innovation (design thinking, design theory). Londres: MIT Press, 2015.

MANZINI, E. Design para a Inovação Social e Sustentabilidade: comunidades criativas, organizações colaborativas e novas redes projetuais. Rio de Janeiro: E-papers, 2008. MANZINI, E., VEZZOLLI, C. O Desenvolvimento de Produtos Sustentáveis: os requisitos ambientais dos produtos industriais. São Paulo: Editora da Universidade de São Paulo, 2002.

MERONI, A. Introduction. In: Creative Communities: people inventing sustainable ways of Living. Milão: Editora PoliDesign, 2007.

UNEP. Product-Service Systems and Sustainability: opportunities for sustainable solutions. Paris: UNEP, 2001. 